\title{
JENIS-JENIS DAN BENTUK T-V YOBIKAKE OLEH REMAJA JEPANG
}

\author{
I Gusti Ayu Putu Istri Aryasuari \\ email: istriaryasuari15@gmail.com \\ Program Magister Linguistik, Universitas Udayana \\ I Ketut Darma Laksana \\ email: darmalaksana27@yahoo.com \\ Program Magister Linguistik, Universitas Udayana \\ Ni Luh Nyoman Seri Malini \\ email:kmserimalini@yahoo.com \\ Program Magister Linguistik, Universitas Udayana
}

\begin{abstract}
Abstrak - Penelitian ini bertujuan untuk mengetahui jenis-jenis sapaan dan bentuk T-V sapaan yang digunakan oleh remaja Jepang. Sumber data yang digunakan, yaitu data berupa kuesioner, daftar pertanyaan, serta didukung dengan data-data yang bersumber dari film Jepang dan kartun Jepang (anime).
\end{abstract}

Teori yang digunakan adalah teori jenis-jenis yobikake menurut Hiromi dan Teori T-V BrownGillman (1960). Metode dan teknik penyediaan data dilakukan dengan kuesioner dan metode wawancara kepada remaja Jepang. Metode dan teknik analisis data dilakukan dengan metode padan referensial. Metode dan teknik penyajian hasil analisis data digunakan metode informal dan formal.

Hasil penelitian, yaitu ditemukan tiga jenis sapaan yaitu sapaan. Ketiga jenis sapaan tersebut, pronomina persona 'ninshoo daimeshi', sapaan nama diri bersufiks/bentuk Mr/Mrs 'keishou', dan sapaan istilah kekerabatan 'shinzoku yougomei'. Sapaan-sapaan tersebut ditemukan mengandung bentuk T-V. Sapaan pronomina persona bentuk T yang ditemukan, yaitu atashi, ore, boku, jibun, wa-shi, a-shi, washitachi, atashitachi, oretachi, uchira, anta, omae, kimi, temee, omaetachi, dan minna. Sapaan pronomina persona bentuk V yang ditemukan, yaitu watakushi, watashi, watashitachi, anata, anatatachi, minasama dan minasan. Sapaan nama diri bersufiks yang mengandung bentuk T, yaitu sapaan dengan sufiks $\sim k u n$ dan chan. Sapaan nama diri bersufiks yang mengandung bentuk V, yaitu sapaan yang mengandung sufiks $\sim$ sama, $\sim$ dono, dan $\sim$ san. Sapaan istilah kekerabatan yang mengandung bentuk T, yaitu ojiichan, jiiji, obaachan, baaba, papa, oyaji, otou, mama, okaa, kaasan, onii, oniichan, oneechan, neechan, dan imoutochan. Sapaan istilah kekerabatan yang mengandung bentuk V, yaitu ojiisan, obaasan, otousan, okaasan, oniisan, ani, ane, otouto, dan imouto.

Kata Kunci-yobikake remaja, jenis yobikake, bentuk T-V sapaan remaja

Abstract - This study aims to determine the types of greetings and forms of T-V greetings used by Japanese teenagers. Sources of data used are data in the form of questionnaires, list of questions, and supported by data sourced from Japanese movies and Japanese cartoons (anime).

The theory used is the theory of types of yobikake according Hiromi and Theory T-V BrownGillman (1960). Methods and techniques of data provision are made with questionnaires and interview methods to Japanese adolescents. Methods and techniques of data analysis are performed by referential reference method. Methods and techniques of presentation of data analysis results use informal and formal methods. 
Result of research shows that there are three kinds of greeting found. The three types of greeting, personal pronouns 'ninshoo daimeshi', greeting of the suffixed name of self / form Mr / Mrs 'keishou', and greeting in the term kinship 'shinzoku yougomei'. The greetings that are found contain the T-V form. Greetings of personal pronoun of the form of $\mathrm{T}$ found are atashi, ore, boku, jibun, wa-shi, a-shi, washitachi, atashitachi, oretachi, uchira, anta, omae, kimi, temee, omaetachi, and minna. Greetings personal pronouns of $\mathrm{V}$ form found are watakushi, watashi, watashitachi, anata, anatatachi, minasama and minasan. The greetings of suffixed self name containing $\mathrm{T}$ shapes are greetings with the suffixes $\sim$ kun and $\sim$ chan. The greetings of suffixed self name containing V-shapes, are greetings with suffixes $\sim$ sama, $\sim$ dono, and $\sim$ san. Greetings in the term kinship that contain the form $\mathrm{T}$ are ojiichan, jiiji, obaachan, baaba, papa, oyaji, otou, mama, okaa, kaasan, onii, oniichan, oneechan, neechan, and imoutochan. Greetings in the term kinship containing the form V, are ojiisan, obaasan, otousan, okaasan, oniisan, ani, ane, otouto, and imouto.

Keywords: yobikake teen, yobikake type, T-V form

\section{PENDAHULUAN}

Yobikake merupakan istilah untuk menyebutkan kata sapaan dalam bahasa Jepang. Yobikakae merupakan kata yang digunakan untuk menegur atau menyapa seseorang atau mitra tutur. Definisi sapaan (yobikake) di bawah ini dikutip dari kamus Koujien Kokugo Jiten Daigoban (dalam Yin, 2008:217):

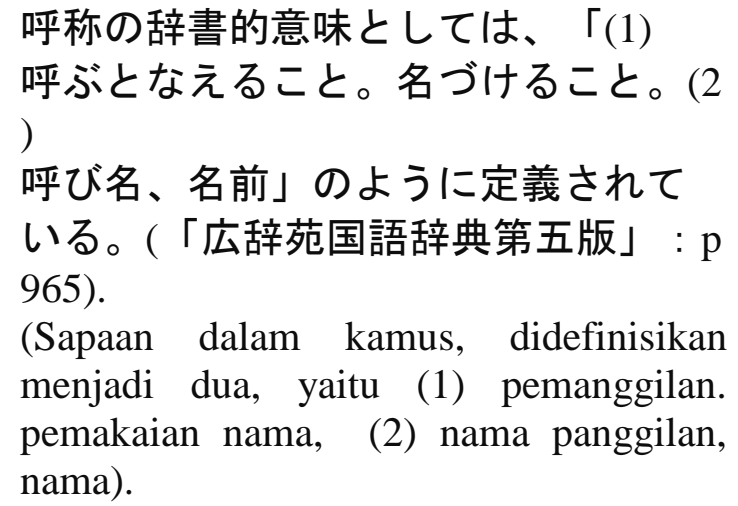

Menurut kamus Koujien Kokugo Jiten Daigoban, sapaan dibagi menjadi dua, yaitu pemanggilan dan pemakaian nama atau nama panggilan orang tersebut. Pemanggilan seseorang ataupun memanggil seseorang dipengaruhi oleh jumlah, kedudukan, usia, gender, hubungan serta jarak sosial dari penutur, mitra tutur, serta orang lain yang dibicarakan. Penggunaan sapaan juga dipengaruhi dengan jenis sapaan yang digunakan kepada mitra tutur.

Menurut Hiromi Imura (dalam Yin, 2008:217), sapaan (yobikake) secara garis besar dibagi menjadi tiga, yaitu ungkapan sapaan dengan cara menyapa berdasarkan daimeshi (terms of address), cara menyapa yang diungkapkan dengan doushi (verbs of adress), cara menyapa berdasarkan meishi (noun of address).

Unsur sapaan lainnya adalah nama diri atau dalam bahasa Jepang disebut dengan koujinmei. Nama diri seseorang di Jepang terdiri atas dua kata, yaitu nama keluarga diikuti dengan nama yang diberikan oleh orang tua. Bentuk nama diri bersufiks merupakan bentuk sapaan untuk menyebut dan menyapa seseorang dengan menggunakan pemarkah hormat atau akrab yang berupa sufiks -sama, -san, -kun, -chan dan-dono (Dewi, 2009:35). Sapaan nama diri bersufiks bahasa Jepang digunakan sesuai dengan hubungan antara penutur dan mitra tutur. Kaiser, Ichikawa, Kobayashi, dan Yamamoto (2002) menyatakan bahwa saat nama seseorang digunakan sebagai kata sapaan, sufiks -san lebih umum digunakan terutama terhadap orang yang 
lebih tua, sedangkan sufiks -chan dan -kun digunakan terhadap anak-anak atau orang yang sangat akrab dengan penutur.

Penggunaan unsur sapaan lain yang digunakan di dalam keluarga adalah unsur istilah kekerabatan. Istilah kekerabatan dalam bahasa Jepang disebut dengan shinzoku yougumei. Istilah kekerabatan merupakan sapaan yang digunakan untuk menunjukkan hubungan darah atau kekerabatan yang dekat. Berdasarkan hal tersebut, penelitian ini meneliti jenis-jenis yobikake yang digunakan oleh remaja Jepang saat ini serta bentuk T-V dari yobikake bahasa Jepang yang digunakan oleh remaja Jepang.

\section{METODE PENELITIAN}

Penelitian ini merupakan penelitian Lokasi penelitian dilakukan di Bali. Sumber data yang digunakan, yaitu data primer yang bersumber dari kuesioner dan daftar pertanyaan yang diajukan kepada sepuluh remaja Jepang, yang berusia 15-24 tahun. Sepuluh remaja Jepang yang dipilih, terdiri atas lima remaja laki-laki dan lima remaja perempuan. Data tersebut juga didukung dengan data yang diambil dari film Jepang dan kartun Jepang.

Metode dan teknik pengumpulan data menggunakan kuesioner dan wawancara. Pada tahap analisis data digunakan metode padan referensial. Metode padan referensial adalah metode yang penentunya adalah kenyataan yang ditunjuk oleh bahasa atau referent bahasa (Sudaryanto, 1993:13). Data yang diperoleh dari kuesioner dan wawancara dianalisis dan dikelompokkan sesuai dengan jenis sapaan menurut teori Imamura Hiromi. Data yang telah dikelompokkan kemudian dianalisis bentuk, fungsi, dan makna sapaan bahasa Jepang. Data yang telah dikumpulkan dan dianalisis disajikan dengan metode informal dan metode formal. Metode informal adalah penyajian data yang telah dianalisis dengan menggunakan kata-kata biasa atau uraian biasa, bukan bagan atau lambang. Sebaliknya, metode formal adalah penyajian data yang telah dianalisis dengan menggunakan tabel-tabel yang diperlukan atau lambang-lambang.

\section{HASIL PENELITIAN DAN PEMBAHASAN}

Hasil analisis berupa analisis jenis-jenis yobikake dan bentuk T-V yobikake yang digunakan oleh remaja.

\section{Jenis-jenis Yobikake}

Jenis-jenis sapaan bahasa Jepang yang ditemukan yang digunakan oleh remaja Jepang dibagi menjadi pronomina persona 'ninshoo daimeshi', nama diri bersufiks/bentuk $M r / M r s$ 'keishou', dan istilah kekerbatan 'shinzoku yougomei'.

\section{Sapaan Pronomina Persona 'Ninshoo Daimeshi'}

Sapaan pronomina persona yang ditemukan dibagi menjadi tiga, yaitu sapaan pronomina persona pertama dan sapaan pronomina persona kedua. Sapaan pronomina persona pertama dibagi lagi menjadi sapaan pronomina persona pertama tunggal dan sapaan pronomina persona pertama jamak. Sapaan pronomina persona kedua dibagi menjadi sapaan pronomina persona kedua tunggal dan sapaan pronomina persona kedua jamak. Sapaan pronomina persona pertama tunggal yang ditemukan, yaitu watakushi 'saya', watashi 'saya', atashi 'aku', ore 'aku', boku 'aku', uchi 'dalam', jibun 'diri', wa-shi 'aku' dan a-shi 'aku'. Sapaan pronomina persona pertama jamak yang ditemukan, yaitu watashitachi 'kami', washitachi 'kami', atashitachi 'kita', oretachi 'kita', dan uchira 'kita'. Sapaan pronomina persona kedua tunggal, yaitu anata 'Anda', anta 'Anda/kamu', omae 'kamu', kimi 'kamu', temee 'kamu'. Sapaan pronomina persona kedua jamak, yaitu anatatachi 'Anda sekalian', minasama 'Anda sekalian', minasan 'Anda sekalian', omaetachi 'kalian', dan minna 'kalian'.

Sapaan Nama Diri Bersufiks/Bentuk Mr/Mrs 'Keishou' 
Nama diri bersufiks yang ditemukan, dan digunakan oleh remaja, yaitu -sama, -dono, san, -kun, dan -chan. Nama diri bersufiks -sama, -dono, dan -san dapat digunakan untuk menyapa atau memanggil lawan bicara laki-laki dan perempuan. Sapaan -chan digunakan untuk memanggil atau menyapa lawan bicara perempuan. Namun dalam penelitian ini ditemukan sapaan ini dapat digunakan untuk menyapa atau memanggil laki-laki.

\section{Sapaan Istilah Kekerabatan 'Shinzoku Yougomei'}

Sapaan istilah kekerabatan yang digunakan oleh remaja untuk menyebut kakek, yaitu ojiisan, ojiichan, dan jiiji. Sapaan untuk menyebut nenek, yaitu obaasan, obaachan, dan baaba. Sapaan untuk menyebut ayah, yaitu otousan, otou, papa, dan oyaji. Sapaan untuk meyebut ibu, yaitu okaasan, okaa, mama, dan kaasan. Sapaan untuk menyebut kakak laki-laki, yaitu ani, oniisan, oniichan, dan onii. Sapaan untuk menyebut kakak perempuan, yaitu ane, oneechan, dan neechan. Sapaan untuk menyebut adik laki-laki, yaitu otouto dan untuk menyebut adik perempuan, yaitu imouto, serta imoutochan untuk menyapa adik perempuan.

\section{Bentuk T-V Sapaan Pronomina Persona}

Sapaan bentuk $\mathrm{T}$ dibagi menjadi sapaan pronomina persona pertama tunggal akrab, sapaan pronomina persona pertama jamak akrab, sapaan pronomina persona kedua tunggal akrab, dan sapaan pronomina persona kedua jamak akrab. Sapaan bentuk V dibagi menjadi sapaan pronomina persona pertama tunggal hormat, sapaan pronomina persona pertama jamak hormat, sapaan pronomina persona kedua tunggal hormat, dan sapaan pronomina persona kedua jamak hormat.

Sapaan pronomina persona pertama tunggal akrab, yaitu atashi, ore, boku, uchi, jibun, wa-shi, dan a-shi. Sapaan atashi hanya digunakan oleh perempuan, sedangkan ore hanya digunakan oleh laki-laki untuk menyebut dirinya.
Di pihak lain boku digunakan oleh laki-laki dan perempuan. Sapaan uchi dan jibun merupakan sapaan yang digunakan oleh perempuan dan lakilaki, sedangkan wa-shi dan a-shi hanya digunakan oleh perempuan untuk menyebut dirinya. Sapaan pronomina persona pertama jamak akrab yang ditemukan yaitu, wa-shitachi, atashitachi, oretachi, dan uchira.

Sapaan wa-shitachi dan atashitachi merupakan sapaan yang hanya digunakan oleh perempuan untuk menyebut pembicara yang berjumlah lebih dari pertama orang. Sapaan oretachi hanya digunakan oleh laki-laki untuk menyebut pembicara yang berjumlah lebih dari satu orang, sedangkan sapaan wa-shitachi digunakan oleh laki-laki dan perempuan untuk menyebut lawan bicara yang berjumlah lebih dari satu orang. Sapaan uchira merupakan sapaan yang digunakan oleh laki-laki dan perempuan untuk menyebut pembicara yang berjumlah lebih dari satu orang.

Sapaan pronomina persona kedua tunggal bentuk akrab yang ditemukan, yaitu anta, omae, kimi, dan temee. Sapaan anta digunakan oleh laki-laki dan perempuan untuk menyebut lawan bicara laki-laki ataupun perempuan. Sapaan omae digunakan oleh laki-laki untuk menyebut lawan bicara laki-laki atau perempuan. Sapaan kimi dan temee digunakan oleh laki-laki atau perempuan untuk menyebut lawan bicara laki-laki. Sapaan pronomina persona kedua jamak akrab yang ditemukan, yaitu omaetachi dan minna. Omaetachi digunakan oleh laki-laki untuk menyebut lawan bicara laki-laki ataupun perempuan yang berjumlah lebih dari satu orang. Minna digunakan oleh laki-laki ataupun perempuan untuk menyebut lawan bicara lakilaki atau perempuan yang berjumlah lebih dari satu orang.

Sapaan pronomina persona pertama tunggal hormat, yaitu watakushi dan watashi. Watakushi dan watashi merupakan sapaan yang digunakan oleh laki-laki ataupun perempuan untuk menyebut dirinya sendiri. Sapaan pronomina persona pertama jamak yang 
ditemukan, yaitu watashitachi. Watashitachi digunakan oleh laki-laki ataupun perempuan untuk menyebut pembicara yang berjumlah lebih dari satu orang. Sapaan pronomina persona kedua tunggal yang ditemukan, yaitu anata yang dapat digunakan oleh laki-laki dan perempuan. Sapaan pronomina persona kedua jamak yang ditemukan yaitu, anatatachi, minasama dan minasan. Sapaan-sapaan tersebut digunakan untuk menyebut lawan bicara laki-laki ataupun perempuan yang berjumlah lebih dari satu orang. pelafalan menunjukkan bahwa tingkat kemampuan pelafalan siswa dalam berbicara bahasa Sasak dapat dilihat pada tabel dibawah ini.

\section{Bentuk T-V Sapaan Nama Diri Bersufiks}

Sapaan nama diri bersufiks $-k u n$ dan chan berbentuk T atau akrab. Sapaan nama diri bersufiks -kun merupakan sapaan nama diri bersufiks yang digunakan oleh laki-laki ataupun perempuan untuk menyapa atau memanggil teman laki-laki. Sapaan sufiks $-k u n$ biasanya digunakan diawali dengan nama keluarga ataupun nama diri. Sufiks -chan digunakan diawali dengan nama keluarga, nama diri, atau suku awal nama diri. Sufiks -chan digunakan oleh laki-laki ataupun perempuan untuk menyapa atau memanggil teman laki-laki ataupun perempuan.

Sapaan nama diri bersufiks -sama, -dono, dan san merupakan sapaan nama diri bersufiks bentuk V atau hormat. Sapaan nama diri bersufiks -sama dan -dono hanya digunakan oleh remaja ketika menulis surat atau surat elektronik kepada atasan dalam bidang bisnis. Sapaan tersebut dapat digunakan untuk menyebut atasan laki-laki ataupun perempuan. Sufiks -san digunakan oleh laki-laki atau perempuan untuk menyapa atau memanggil laki-laki atau perempuan yang baru dikenal atau orang yang dihormati. Sufiks -san digunakan diawali dengan nama keluarga atau nama diri.

\section{Bentuk T-V Sapaan Istilah Kekerabatan}

Sapaan istilah kekerabatan dibagi menjadi bentuk T dan bentuk V. Sapaan istilah kekerbatan bentuk $\mathrm{T}$ merupakan sapaan yang bersifat akrab yang digunakan ketika hubungan pembicara dan lawan bicara dekat. Sapaan istilah kekerabatan bentuk $\mathrm{T}$ ditandai dengan adanya sufiks -chan walaupun diawali dengan atau tanpa prefiks kehormatan $o$-. Sapaan istilah kekerabatan untuk kakek bentuk T, yaitu ojiichan dan jiiji. Sapaan ojiichan dan jiiji digunakan oleh penutur yang memiliki hubungan yang sangat dekat dengan lawan bicara, sama halnya dengan sapaan istilah kekerabatan untuk nenek, yaitu obaachan dan baba.

Sapaan istilah kekerabatan ayah, yaitu papa, oyaji, dan otou. Papa merupakan sapaan yang bukan tradisi sapaan bahasa Jepang, tetapi diadopsi dari kebudayaan barat, sama halnya dengan sapaan untuk ibu, yaitu mama. Okaa dan kaasan merupakan sapaan yang digunakan untuk menyapa atau menyebut ibu. Oyaji merupakan sapaan untuk menyebut ayah/bapak. Otou merupakan sapaan yang digunakan untuk menyapa ayah.

Sapaan istilah kekerabatan untuk menyebut kakak laki-laki yaitu oniichan. Sapaan ini menunjukkan hubungan pembicara dan lawan bicara sangat dekat. Sapaan istilah kekerabatan lainnya untuk menyebut kakak perempuan, yaitu oneechan dan neechan. Sapaan oneechan dan neechan digunakan oleh penutur untuk menyapa atau menyebut kakak perempuan. Beberapa remaja menggunakan sapaan nama diri bersufiks untuk menyebut atau memanggil/menyapa kakak perempuan. Sapaan yang digunakan untuk menyebut atau menyapa adik laki-laki yang ditemukan, yaitu nama diri $+\sim k u n$, sedangkan sapaan yang digunakan untuk menyebut atau menyapa adik perempuan, yaitu imoutochan dan nama diri + chan.

Sapaan istilah kekerabatan bentuk V merupakan sapaan istilah kekerabatan yang bersifat hormat atau sopan. Sapaan bentuk V ditandai dengan prefiks penghormatan $o$ - ataupun tidak dan sufiks -san. Sapaan istilah kekerabatan 
kakek bentuk V, yaitu ojiisan, sama halnya dengan sapaan istilah kekerabatan nenek, yaitu obaasan. Sapaan istilah kekerabatan ayah, yaitu otousan, sedangkan sapaan untuk menyebut ibu, yaitu okaasan.

Ani merupakan sebutan untuk menyebut kakak laki-laki, sedangkan ane digunakan untuk menyebut kakak perempuan Sapaan untuk menyebut atau menyapa kakak laki-laki lainnya, yaitu onii. Otouto digunakan untuk menyebut adik laki-laki, sedangkan simoutu digunakan untuk menyebut adik perempuan.

\section{SIMPULAN}

Berdasarkan hasil penelitian yang dilakukan, diperoleh beberapa simpulan sebagai berikut.

1. Jenis-jenis sapaan bahasa Jepang yang ditemukan dan digunakan oleh remaja Jepang dibagi menjadi pronomina persona 'ninshoo daimeshi', nama diri bersufiks/bentuk Mr/Mrs 'keishou', dan istilah kekerbatan 'shinzoku yougomei'.

2. Sapaan pronomina persona satu yang memiliki bentuk $\mathrm{T}$, yaitu atashi, ore, boku, uchi, jibun, wa-shi, a-shi, washitachi, atashitachi, oretachi, dan uchira. Sapaan pronomina persona satu yang memiliki bentuk V, yaitu watakushi, watashi, dan watashitachi. Sapaan pronomina persona dua yang memiliki bentuk T, yaitu anta, omae, kimi, temee, omaetachi, dan minna. Sapaan pronomina persona dua yang memiliki bentuk $\mathrm{V}$, yaitu anata, anatatachi, minasama, dan minasan.

3. Bentuk T sapaan nama diri bersufiks yang ditemukan ,yaitu sapaan yang mengandung nama diri bersufiks $\sim k u n$ dan chan. Penggunaan sapaan tersebut digunakan untuk menyebut atau menyapa lawan bicara yang memiliki status sama atau lebih rendah, usia sama atau lebih muda, ada hubungan kekerabatan yang dekat, serta digunakan dalam konteks tidak formal. Bentuk V sapaan nama diri bersufiks yang ditemukan, yaitu sapaan nama diri yang mengandung sufiks $\sim$ sama, $\sim$ dono, dan $\sim$ san.

4. Sapaan istilah kekerabatan yang memiliki bentuk $\mathrm{T}$ untuk menyebut anggota keluarga, yaitu ojiichan, jiiji, obaachan, baaba, papa, oyaji, otou, mama, okaa, kaasan, onii, oniichan, oneechan, neechan, nama diri $+\sim k u n$, imoutochan dan nama diri $+\sim$ chan. Sapaan istilah kekerabatan yang mengandung bentuk $\mathrm{V}$ yang ditemukan, yaitu ojiisan, obaasan, otousan, okaasan, oniisan, ani, ane, otouto, dan imouto.

\section{DAFTAR PUSTAKA}

Brown, R.W. dan Gilman, A. 1960. "The Pronouns of Power and Solidarity".

Dalam Fishman, J.A, ed., Readings in Sosiology of Language. Paris: Mouton, hlm 252-275.

Dewi, N.M.A.A. 2009. "Sapaan Bahasa Jepang: Bentuk, Fungsi, dan Makna”. (Tesis). Denpasar: Universitas Udayana.

Fischer, J.L. 1964. "Words for Self and Others in Some Japanese Families".

Amerika : Tulane University diunduh pada tanggal $\quad 16 \quad$ November 2016. http://onlinelibrary.wiley.com/doi/10.1525/aa .1964 .66 .suppl_3.02a00070/pdf

Halidia, K. B. dan F. N. Utorodewo. 2013. "Penggunaan Kata Sapaan Bahasa Jepang dalam Novel Saga no Gabai Bachan Karya Yoshichi Shimada" (Tesis). Depok: Kajian Wilayah Jepang, Program Pascasarjana Universitas Indonesia.

Kaiser, S, Yasuko I, Noriko K, Hilofumi Y. 2002. Japanese: A comprehensive grammar. New York: Routledge. 
LINGUISTIKA, SEPTEMBER 2018

p-ISSN: 0854-9613

Vol. 49. No. 25

Yin, Ch. 2008. "Koujien Kokugo Jiten

Daigoban".

Http://hdl.handle.net/10083/35152. 